\title{
Salivary scanning in rheumatoid arthritis with sicca syndrome
}

\author{
JULIEN P. DE JAGER, ' DANIEL CHOY, ${ }^{2}$ AND ANTHONY FLEMING' \\ From the Departments of ${ }^{I}$ Rheumatology and ${ }^{2}$ Nuclear Medicine, the Prince Henry and Prince of Wales \\ Hospital Group, Sydney, Australia
}

SUMMARY Forty-nine patients were studied prospectively by salivary scanning to assess the value of this investigation in possible Sjögren's syndrome (SS). Twenty-three had rheumatoid arthritis (RA) with sicca symptoms and a positive Schirmer's test. Fifteen had RA with no sicca symptoms and a negative Schirmer's test. Eleven had osteoarthrosis (OA) with no sicca symptoms and a negative Schirmer's test. Scanning differentiated only poorly between the three groups. We conclude that it has only limited application in the diagnosis of SS associated with RA.

Salivary scanning is commonly used as an investigatory method to support the diagnosis of Sjögren's syndrome (SS) for both clinical and research purposes. Studies have shown its value in assessing xerostomia. $^{1-5} \mathrm{SS}$ is one of the most frequent systemic complications of rheumatoid arthritis (RA), but the role of salivary scanning in defining this particular condition is still not clear. Early studies $^{267}$ found it to be a sensitive, safe, and objective means of evaluating drying in RA, and these claims have subsequently been reiterated..$^{3-589}$ However, some reports have questioned this. ${ }^{1011}$ In view of the importance of SS in the overall assessment of rheumatoid patients we have attempted to evaluate the discriminatory power of scanning in rheumatoid patients with and without symptoms of drying, using as controls patients with osteoarthrosis (OA) with no evidence of drying. We used exacting techniques in a prospective study analysing both uptake and discharge in parotid and submandibular glands.

\section{Patients and methods}

Patients were divided into three groups. Group 1 consisted of 23 patients (19 female, 4 male) with RA, symptoms of dry eyes or mouth, and a positive Schirmer's test. Mean age was 61.9 years (range of 26 to 85 ), and mean duration of RA was 14 years (range 4 months to 60 years). Group 2 consisted of 15 RA patients (10 females, 5 males) with no

Accepted for publication 23 January 1984.

Correspondence to Dr A. Fleming, Department of Rheumatology, Prince Henry Hospital, Little Bay, Sydney, NSW 2036, Australia. symptoms of drying and a negative Schirmer's test. Mean age was 58.6 years (range 38 to 73 ), and mean duration of RA was 9.9 years (range 8 months to 29 years). Group 3 consisted of 11 patients ( 9 females, 2 males) with primary generalised osteoarthrosis, no symptoms of drying, and a negative Schirmer's test. Mean age was 61.5 years (range 53 to 78 ), and mean duration of OA was 6.7 years (range 1 to 29 years). All RA patients were classical or definite. ${ }^{12}$ The Schirmer's tear test (as supplied by Cooper Health Products Ltd, Aylesbury, Bucks HP22 4JU) was considered positive if less than $10 \mathrm{~mm}$ wetting occurred in either eye in 5 minutes. In-vitro thyroid function tests were performed at the time of the scan (T3, T4, FT1).

Each patient received $75 \mathrm{MBq}$ of sodium pertechnetate $\left({ }^{99 \mathrm{~m}} \mathrm{Tc}\right)$ intravenously. Ten minutes after the injection the images were obtained on a gamma camera equipped with a high sensitivity collimator with the patient supine and the neck hyperextended. The parotid, submandibular, and thyroid glands were included in the field. A Polaroid analogue picture was obtained, and simultaneously information was collected on a Digital Gamma 11 computer with a $64 \times 64$ matrix over 5 minutes. Regions of interest were drawn over the two parotid glands, the two submandibular glands, and the thyroid gland. The patient was then given two lemons to suck, and after 5 minutes the scanning procedure was repeated. Care was taken to ensure that the regions of interest corresponded to the first part of the procedure. A neck:thigh ratio was obtained to assess thyroid uptake, and at the conclusion of the study $400 \mathrm{mg}$ of potassium perchlorate was given to 
each patient. Those patients found to have abnormal thyroid tests and/or abnormal neck:thigh ratios were excluded from the study. The average count per matrix cell of each region of interest of each study was obtained and the salivary gland uptake expressed as a percentage of activity of the thyroid gland. The discharge value was the percentage of the initial activity excreted after lemon stimulation. Data were analysed by Student's t test.

\section{Results}

The uptake and discharge values for the parotid glands are shown in Fig. 1 and the submandibular glands in Fig. 2. The left and right glands have been summed and averaged for the final values with the usual difference between left and right corresponding glands being less the $5 \%$. These data are summarised in Table 1. The results demonstrate the large variation between individual patients in each group and the small differences in the mean values between groups.

\section{PAROTID}
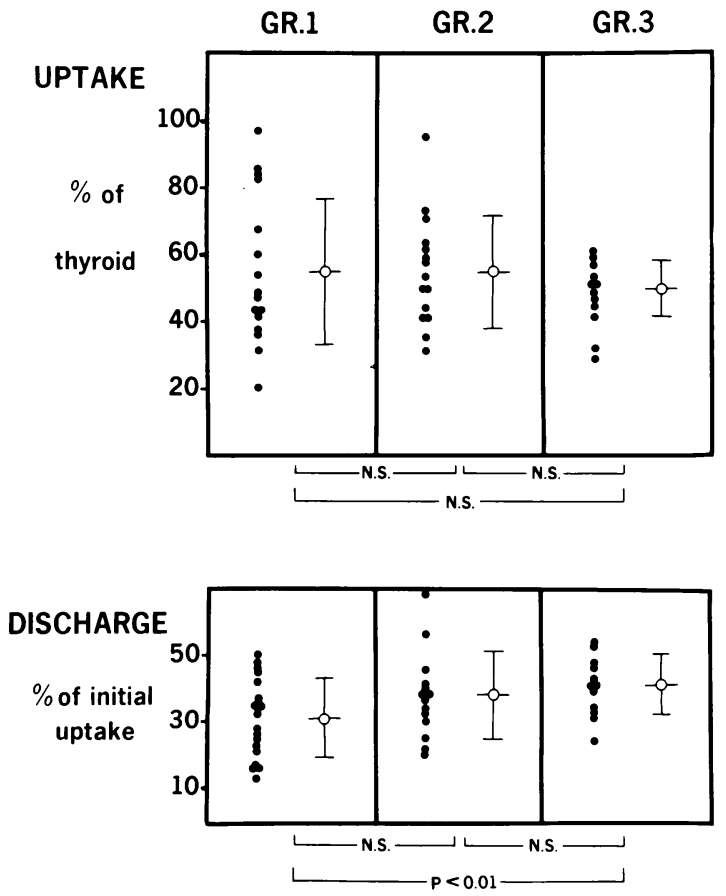

Fig. 1 Parotid uptake and discharge values for the three groups. $N S=$ difference not significant.
SUBMANDIBULAR
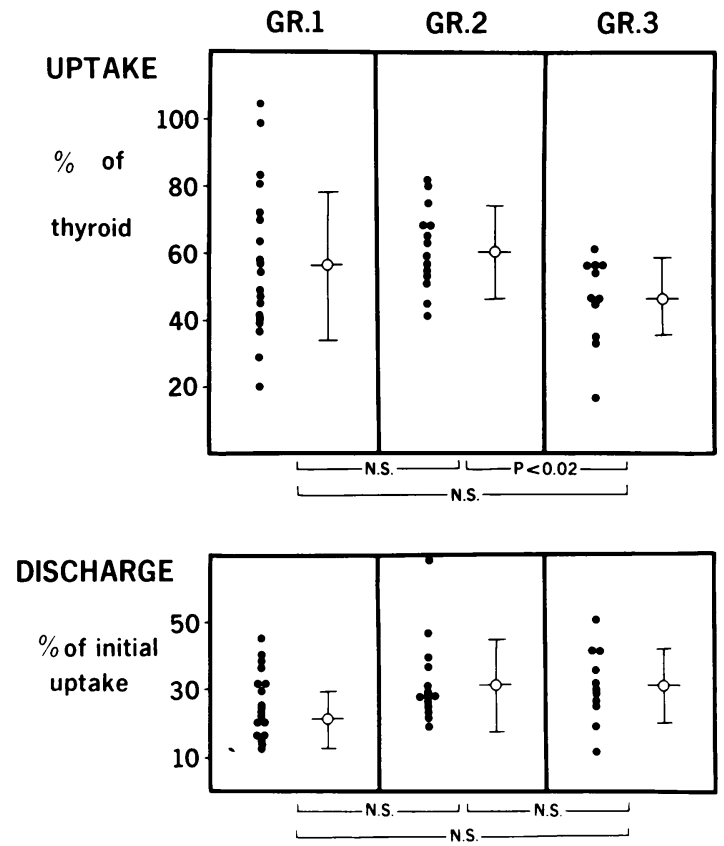

Fig. 2 Submandibular uptake and discharge values for the three groups. $N S=$ difference not significant.

Table Mean and standard deviation of uptake and discharge of parotid and submandibular glands in the three groups. Uptake is expressed as a percentage of thyroid uptake. Discharge is expressed as a percentage of initial salivary gland uptake.

\begin{tabular}{llllll}
\hline & \multicolumn{2}{c}{ Parotid } & & \multicolumn{2}{c}{ Submandibular } \\
\cline { 2 - 3 } \cline { 5 - 6 } \cline { 5 - 6 } & Uptake & Discharge & & Uptake & Discharge \\
\hline $\begin{array}{l}\text { Group 1 } \\
\quad 23 \text { patients }\end{array}$ & $56 \pm 22$ & $31 \pm 10$ & $56 \pm 22$ & $26 \pm 10$ \\
$\begin{array}{l}\text { Group 2 } \\
\quad 15 \text { patients }\end{array}$ & $55 \pm 17$ & $38 \pm 13$ & $60 \pm 14$ & $32 \pm 14$ \\
$\begin{array}{l}\text { Group 3 } \\
11 \text { patients }\end{array}$ & $50 \pm 8$ & $42 \pm 9$ & & $46 \pm 12$ & $31 \pm 11$ \\
\hline
\end{tabular}

\section{Discussion}

Our results suggest only a very limited place for salivary scanning in the investigation of possible SS. Indeed, this technique could scarcely help us to distinguish between three quite different clinical groups, namely, patients with RA who have evidence of drying and patients with both RA and those with OA who have no evidence of drying - 
much less make a diagnosis in the individual patient. These findings do not support the widespread belief that scanning is a valuable tool in this situation and are more in conformity with the work of Kassan and Gardy ${ }^{10}$ and Katz et al. ${ }^{11}$

The significant difference in submandibular uptake between groups 2 and 3 is not easily explained as neither of these groups had sicca symptoms, but there may be good theoretical reasons why uptake studies are an unreliable method of examining gland function. In the possibly analogous situation of thyroid scanning in hypothyroidism factors other than function may affect uptake results. These factors include total iodine pool, drugs, and even age. ${ }^{13}$ Similar conditions could also apply to salivary gland uptake as it handles ions such as $\mathrm{Tc}$ in an identical fashion. ${ }^{13}$ If this is so, then information of potentially greater value in the investigation of SS may well be obtained by studying in more detail the discharge phase of the salivary gland..$^{5}$

We conclude that salivary scanning is of little value in possible SS associated with RA whether to define large groups for research purposes or to diagnose this condition in an individual.

We thank the Department of Medical Illustration, University of New South Wales Hospital Group, for the illustrations, and Mrs Daphne Williams, who prepared the manuscript.

\section{References}

1 Stephen $\mathrm{K}$ W, Chisholm D $M$, Harden $R$ Mc G Robertson J W K, Whaley K, Stuart A. Diagnostic value of quantitative scintiscanning of the salivary glands in Sjögren's and rheumatoid arthritis. Clin Sci 1971; 41: 555-61.

2 Schall G L, Anderson L G, Wolf R O, et al. Xerostomia in Sjögren's syndrome. JAMA 1971; 13: 2109-16.

3 Daniels $T$ E. Powell $M$ R. Sylvester $R$ A. Talal N. An evaluation of salivary scintigraphy in Sjögren's syndrome. Arthritis Rheum 1979; 22: 809-14.

4 Ohrt H J, Schafer R B. An atlas of salivary gland disorders. Clin Nucl Med 1982; 7: 370-6.

5 Baum S, Scheff A M. Editorial: Salivary gland imaging. Clin Nucl Med 1982; 7: 386.

6 Schall G L, DiChiro G. Clinical usefulness of salivary gland scanning. Semin Nucl Med 1972, 2, 3: 270-277.

7 Schall G L (discussant). Cummins N A (moderator). NIH Conference. Sjögren's syndrome - newer aspects of research, diagnosis and therapy. Ann Intern Med 1971; 75: 937-50.

8 Alspaugh M A, Whaley K. In: Kelley W N, Harris E D, Ruddy S, Sledge C B, eds. Textbook of rheumatology. Philadelphia: Saunders, 1981 1: 978.

9 Mishkin F S. Radionuclide salivary gland imaging. Semin Nucl Med 1981; 11: 258-65.

10 Kassan S S. Gardy M. Sjögren's syndrome, an update and overview. Am J Med 1978; 64: 1037-46.

11 Katz W A. Ehrlich G E, Gupta V P. Shapiro B. Salivary gland dysfunction in systemic lupus erythematosus and rheumatoid arthritis. Arch Intern Med 1980; 140: 949-51.

12 Ropes M W, Bennett G A, Cobb S. Jacox R, Jessar R A. 1958 revision of diagnostic criteria for rheumatoid arthritis. Bull Rheum Dis 1958; 9: 175-6.

13 Taurog A. In: Werna S C. Ingba S H. eds. The thyroid: $A$ fundamental and clinical text. 4th ed. New York: Harper and Row, 1978: 33. 